УДК 338.2:502 + 504.03(99) + 316.4

$10.17213 / 2075-2067-2020-5-91-97$

\title{
ДИФФЕРЕНЦИАЦИЯ СТРАТЕГИЙ ЗАНЯТОСТИ МОЛОДЕЖИ В РОССИЙСКИХ РЕГИОНАХ: ОБЪЕКТИВНЫЕ И СУБЪЕКТИВНЫЕ ФАКТОРЫ
}

\author{
(C) 2020 г. $\quad$ Г. E. Косач
}

\section{Южнно-Российский государственный политехнический университет (НПИ) имени М. И. Платова, г. Новочеркасск, Россия}

Целью исследования является определение и раскрытие объективных и субъективных факторов, влияюших на разделение стратегий занятости молодежного населения Российской Федерации в различных регионах страны в современный промежуток времени, а также изучение институциональной основы реализации подхода органов исполнительной и законодательной власти государства кукреплению профессионализации молодељси и локализачии ее прекаризаџии.

Методология исследования базируется как на теоретических способах познания, таких как анализ и синтез социологчческого знания, так и на практических методах математической статистики и эконометрики. Совместное использование теоретических и практических подходов дает возможность изучить весь комплекс стратегий индивидуумов на рынке труда, а также выработать предложения по дальнейшему целевому управляющему воздействию на процесс дифференциации указанных стратегий.

Результаты исследования. Одним из основных результатов работы является определение объективных и субъективных факторов дифференциации стратегий занятости молодежи в российских регионах. Важность описанных процессов конкретизирует перед социальными науками проблему определения региональных, наџиональных и общегосударственных особенностей в подходах к выбору молодежью текущей и будущей профессии. Согласно исследованию, ведущие субъекты Российской Федераџии лишь в последние годы определили необходимость регуляторной функции региональных органов власти на рынке труда. Вместе с тем в результате исследования установлено, что современное развитие маневрирования трудовых ресурсов характеризуется стихийностью и подчас хаотичностью их динамики.

Перспектива исследования состоит в дальнейшем углубленном сочиологическом анализе стратегий занятости молодежи в российских регионах и выработке практических методов воздействия на данные процессы со стороны органов государственной власти.

Ключевые слова: депрофессионализаџия; соџчим; молодежь; стратегии занятости; прекаризащия.

\section{DIFFERENTIATION OF YOUTH EMPLOYMENT STRATEGIES IN THE RUSSIAN REGIONS: OBJECTIVE AND SUBJECTIVE FACTORS}

\author{
(C) 2020 G. E. Kosach
}

\section{Platov South Russian State Polytechnic University (NPI), Novocherkassk, Russia}

The purpose of the research is to identify and disclose objective and subjective factors that affect the division of employment strategies of the youth population of the Russian Federation 
in different regions in the modern period of time, as well as to study the institutional basis for implementing the approach of the Executive and legislative authorities of the state to strengthen the professionalization of youth and localize its precarization.

The research methodology is based on both theoretical methods of knowledge, such as the analysis and synthesis of sociological knowledge, and practical methods of mathematical statistics and econometrics. The combined use of theoretical and practical approaches makes it possible to study the entire range of strategies of individuals in the labor market, as well as to develop proposals for further targeted management influence on the process of differentiation of these strategies.

Research result. One of the main results of the work is the identification of objective and subjective factors of differentiation of youth employment strategies in Russian regions. The importance of the described processes concretizes the problem of determining regional, national and state characteristics in approaches to the choice of current and future professions by young people in the social Sciences. According to the study, the leading regions of the Russian Federation have only recently identified the need for a regulatory function of regional authorities in the labor market. At the same time, as a result of the research, it is established that the modern development of maneuvering of labor resources is characterized by spontaneity and sometimes chaotic dynamics.

The prospect of the study consists in further in-depth sociological analysis of youth employment strategies in Russian regions and development of practical methods for influencing these processes by public authorities.

Key words: deprofessionalization; society; youth; employment strategies; precarization.

Введение. В экономических, психологических и социальных науках принято выделять молодых жителей государства как самую значительную социальную группу, оказывающую воздействие на весь процесс экономического, трудового и социального воспроизводства. Уникальные свойства населения младше 29 лет делают его самым востребованным в обеспечении прорыва в развитии государства, так как оно является ключевой основой общественного воспроизводства и экономических изменений. Процесс выбора стратегий занятости и включения молодежи в социальные процессы характеризуется многовариативностью и появлением ранее неизвестных моделей адаптационного поведения, а также симбиозом устаревших и инновационных стратегий профессионального самоопределения в условиях современности.

Для молодежи в российском обществе создаются условия для сознательного выбора профессии и успешного карьерного роста. Важность обеспечения условий для сознательного выбора молодежью профессии подчеркнута в ежегодном Послании Президента Российской Федерации В.В. Путина
Федеральному собранию РФ [1] в январе 2020 года.

Президент Российской Федерации отмечает необходимость не только поступательного увеличения показателей приема абитуриентов в российские образовательные учреждения, но и включения работодателей и участников бизнес-сообществ в развитие высших учебных заведений в регионах страны. Данные действия должны включать укрепление социальной, учебной, исследовательской инфраструктуры субъектов федерации, системы непрерывной и динамической подготовки, переподготовки и повышения квалификации профессорско-преподавательского состава.

Однозначно определена потребность в получении современных знаний, чтобы обучающиеся имели возможность начать успешную карьеру в своем регионе. Для этих целей высшая школа обязана гибко и своевременно реагировать на запросы рынка труда и социума. Кроме того, дана установка на возможность смены направления и программы обучения студентов после второго года обучения. 
Стратегии занятости молодежи. Институциональной основой реализации данной стратегии является укрепление взаимодействия образовательных учреждений, индустриальных партнеров и органов местной, региональной и государственной власти.

Дальнейшую реализацию описанного направления можно рассмотреть на примере Южно-Российского государственного политехнического университета (НПИ) имени М. И. Платова (далее - ЮРГПУ (НПИ). Так, в указанном высшем учебном заведении создано Управление по взаимодействию с работодателями, основными задачами которого являются:

- координация работы высшего учебного заведения и индустриальных партеров по обеспечению трудоустройства студентов и выпускников;

— анализ рынка труда на территории города, региона, округа;

— анализ текущего состояния образовательных услуг у конкурентов;

- налаживание партнерских отношений с производственными организациями, образовательными учреждениями высшего и средне-профессионального образования, органами исполнительной власти, а также службой занятости населения Российской Федерации;

- развитие и поддержание стабильного функционирования информационной системы помощи в трудоустройстве выпускников;

- создание и осуществление рекламной политики в сфере профессионального и дополнительного образования [2].

Реализацией данных задач стало заключение договоров о трудоустройстве выпускников ЮРГПУ (НПИ) с 9 научно-образовательными организациями, 11 энергетическими предприятиями, 14 предприятиями химической промышленности, 10 предприятиями машиностроения, 5 крупными предприятиями пищевой промышленности, 5 горнодобывающими и нефтегазовыми предприятиями, 4 приборостроительными компаниями, 3 организациями строительной отрасли, 36 предприятиями различных форм собственности и направленности. Принято решение о ежегодном проведении дней открытых дверей и ярмарок вакансий.

Вместе с тем, как отмечают в своей статье Ю.В. Голиусова и Г.А. Ключарев [3], после завершения обучения в высшем или среднеспециальном учебном заведении трудоустраиваются от 30 до 60 процентов выпускников. Большая часть остальной молодежи продолжает оставаться на иждивении родителей, поэтому работа по включению молодого трудоспособного населения в рабочий процесс ложится также на плечи региональных властей. Так, Правительство Ростовской области в 2019 году внесло изменения в список востребованных профессий на рынке труда [4]. Данная мера позволила определить и финансировать в первую очередь те специальности, трудоустройство с которыми имеет наибольший шанс на успех. Однако, данный список включает в себя исключительно специальности среднего профессионального образования и полностью игнорирует выпускников высших учебных заведений. Это объясняется тем, что для региона характерна потребность в выпускниках рабочих специальностей. Как отмечают Э. Д. Рубинская и И.Н. Савченкова [5], для Ростовской области характерен перекос на рынке труда, который определяется разницей в предложении и спросе на специалистов различных профессий. Однако, в различных регионах государства трудовой рынок значительно отличается и имеет свои ключевые особенности.

Региональная дифференциация занятости. В социологических науках принято выделять объективные и субъективные факторы дифференциации [6]. Следует отметить, что российские регионы и территории имеют различия, которые являются объективными причинами дифференциации направлений и стратегий занятости молодежи. В первую очередь, это географические, природно-климатические, экономические, этнокультурные, национальные особенности, статус видов деятельности и традиционные виды занятий.

К субъективным причинам дифференциации стратегий занятости относят сознательный выбор молодежью специальности, готовность к непрерывному повышению квалификации, горизонтальная профессиональная мобильность. Важным является создание на предприятии системы работы с молодыми специалистами с целью их закрепления на производстве, развитие института наставничества. 
Нередко субъективные факторы оказывают решающее воздействие на выбор профессии. В условиях сформированного свободного и практически нерегулируемого рынка труда молодые выпускники учебных заведений разных уровней профессионального образования предстают перед выбором между более высоким уровнем оплаты труда и более высокими перспективами будущего карьерного роста. Данный выбор приходится осуществлять в условиях колоссального социального неравенства разных профессий на трудовом рынке, а также дифференциации прав и гарантий внутри одной профессиональной группы, на первый взгляд, равной по всем формальным признакам, таким как профессиональная квалификация и уровень образования [7].

Стоит отметить, что наибольшие показатели миграционной активности приходятся на молодежь в возрасте 15-24 года. Уровень региональной миграции в указанной возрастной группе также является максимальным. Данный фактор прямо коррелирует с объективными региональными экономическими условиями. Вместе с тем имеется сильная корреляционная зависимость между показателями занятости молодежи и размещением учебных заведений на данной территории (в первую очередь вузов), а также дислокацией военных частей.

Анализ статистических данных показывает, что дислокация воинских формирований, в отличие от многих государств, в Российской Федерации является важным объективным фактором дифференциации молодежной занятости. Так, согласно самым свежим имеющимся статистическим данным (январь 2018 года) Ростовстата [8], являющегося органом Федеральной службы государственной статистики, наименьшая безработица среди молодежи наблюдается в муниципальных образованиях Ростовской области с наибольшим количеством воинских частей, прослеживается сильная прямая корреляционная зависимость. Наибольшее количество воинских частей (согласно открытым данным Министерства обороны Российской Федерации) в Ростовской области сконцентрировано в г. Новочеркасске, Аксайском и Октябрьском районах Ростовской области, г. Батайске, а также в г. Ростове-на-Дону. При этом по- казатель молодежной безработицы в данных муниципальных образованиях превышает 5 процентов только в г. Батайске, а в г. Новочеркасске он зарегистрирован на уровне 0,89 процентов. Вместе с тем стоит учитывать, что в г. Новочеркасске низкий показатель безработицы молодых людей образован синергетической силой большого количества факторов дифференциации, каждый из которых взаимно усиливает друг друга. Так, наличие в указанном муниципальном образовании двух крупных градообразующих высших учебных заведений, присутствие военного учебного центра при одном из учебных заведений, выпускающего командный и офицерский состав, а также относительно большое количество воинских частей взаимно усиливают эффект снижения уровня безработицы.

В отличие от занятости всего трудоспособного населения на занятость молодежи оказывает сильное влияние объективный фактор распределения по территории региона средне-специальных и высших учебных заведений. В муниципальных образованиях с высоким относительным коэффициентом присутствия учебных заведений формируется активный рынок предложения развлекательных и увеселительных услуг, развивается сфера заведений быстрого питания, кафе, прачечных, салонов красоты, типографий и т.п. В описанных городах и поселениях создано множество рабочих мест сферы услуг, что значительно превосходит предложение на рынке труда в промышленных центрах.

3.А. Капелюк и С.Д. Капелюк [9] отмечают важный объективно-субъективный фактор сегрегации по национальному признаку при распределении рабочих мест. Наблюдается значимая дискриминация национальных меньшинств при приеме на работу. Тем самым в регионах с выраженной сегрегацией по национальному признаку межрегиональный трансфер молодежной рабочей силы из регионов с иным национальным составом значительно уменышается. Вместе с тем данный фактор подталкивает трудоспособное население национальных менышинств в регионах мигрировать в регионы, где их этнос преобладает.

Изучая вопросы межрегиональной дифференциации трудовой занятости населения в Российской Федерации, невозможно не принимать во внимание объективный кли- 
матический фактор. В связи с тем, что в стране представлены почти все климатические зоны (за исключением тропической и экваториальной), занятость в разных природных условиях сильно отличается. Предприятиям, находящимся в районах Сибири и крайнего Севера, приходится избыточно мотивировать работников повышенными заработными платами, возможностями быстрого карьерного роста, расширенным социальным пакетом. Однако в современном информационном обществе работодатели в данных регионах все же обладают низкой привлекательностью для молодых специалистов. При этом работодатели в южных регионах и мегаполисах испытывают на себе повышенное предложение трудовых ресурсов, это в конечном итоге приводит к снижению уровня оплаты труда, что при низком вмешательстве государства, наблюдаемом в данный момент, указывает на сформировавшийся свободных рынок спроса и предложения трудовых ресурсов.

При изучении вопроса занятости молодежи отдельного внимания заслуживают регионы с высокой долей молодого трудоспособного населения. В Российской Федерации наибольший показатель молодежи зарегистрирован в регионах Северо-Кавказского федерального округа. К.А. Омарова в исследованиях рынка труда в кавказских регионах [10] фиксирует значительное превышение предложения рабочей силы над спросом (86процентных пункта). Данные факторы привели как к самым низким уровням оплаты труда по сравнению с другими субъектами Федерации, так и практической невозможности найти работу молодому специалисту в выбранной отрасли, что повлекло за собой высокий отток молодых кадров из региона. Учитывая данный аспект и факт сегрегации по национальному признаку в других регионах, который описан ранее, миграция трудовых ресурсов из республик Северного Кавказа приводит к увеличению уровня безработицы в регионах Южного федерального округа, что ежегодно фиксируется в отчетах органами Федеральной службы государственной статистики.

Таким образом, органам исполнительной власти Южного федерального округа, осуществляющим свою деятельность в области планирования занятости населения, целесообразно выработать предложения по трудоустройству молодежи, прибывшей из соседних регионов, в целях недопущения роста безработицы.

Заключение. Подводя итоги научной работы, можно сделать вывод о том, что занятость молодого населения представляет собой актуальную проблему для Российской Федерации в 2020 году. Молодежь, являющаяся социальной группой, которая оказывает наибольшее воздействие на процесс экономического, трудового и социального воспроизводства, является в то же время и самой уязвимой группой при распределении трудовых мест. Объективные и субъективные факторы дифференциации занятости на абсолютно свободном рынке труда, наблюдающемся в последние годы, создают перекос в сторону наиболее привлекательных регионов, что в конечном итоге отразится не только на социальном, но и на экономическом развитии субъектов Федерации. Меры поддержки стратегий занятости, описанные на примеpe ЮРГПУ (НПИ), нуждаются в ежегодном совершенствовании и включении в данный процесс муниципальных, региональных и федеральных властей. Своевременная поддержка молодых специалистов должна стать приоритетным направлением в политике регионов на ближайшее десятилетие.

\section{Литература}

1. Послание Президента РФ Федеральному Собранию от 15.01.2020 г. «Послание Президента Федеральному Собранию».

2. Управление по взаимодействию с работодателями. Официальный сайт ЮРГПУ (НПИ). [Электронный ресурс] - Режим доступа: https://www.npi-tu.ru/index.php?id=111.

3. Голиусова Ю. В., Ключарев Г. А. О стратегиях занятости современной молодежи// Россия реформирующаяся. - 2017. №15. - C. 72-90.

4. Постановление Правительства Ростовской области от 15 февраля 2016 г. №80 «Об утверждении Регионального перечня наиболее востребованных на рынке труда, новых и перспективных профессий и специальностей, требующих среднего профессионального образования».

5. Рубинская Э.Д., Савченкова И.Н. Рынок труда Ростовской области и иностранные 
студенты: новые подходы к решению проблем дефицита рабочей силы // Вестник Ростовского государственного экономического университета (РИНХ). — 2017. — №1 (57). — С. 47-55.

6. Нуртдинова А. Ф., Чиканова Л. А. Дифференциация регулирования трудовых отношений как закономерность развития трудового права // Журнал российского права. 2015. — №6 (222). — С. 68-82.

7. Саксельц̧ева Л.Я., Тарский Ю. И. Проблемы занятости и трудоустройства молодежи в фокусе социологии // Вестник ПАГС. 2016. 一 №4 (55). - С. 85-91.

8. Рынок труда и занятость населения. Федеральная служба государственной статистики [Электронный ресурс] - Режим доступа: https://rostov.gks.ru/folder/29049.

9. Капелюк 3. А., Капелюк С.Д. Исследование роли экономических факторов в дифференциации занятости населения // Общество: политика, экономика, право. - 2019. №2 (67). - С. 25-29.

10. Омарова К.А., Куиченко Д. С., Нурмагомедова Р.К. Рынок труда Северо-Кавказского федерального округа: анализ ситуации и содействие региональной занятости // РППЭ. — 2018. — №12 (98). — С. 260-267.

\section{Reference}

1. Poslanie Prezidenta RF Federal'nomu Sobraniju ot 15.01.2020 g. «Poslanie Prezidenta Federal'nomu Sobraniju» [Message of the President of the Russian Federation to the Federal Assembly of 15.01.2020 «Message of the President to the Federal Assembly»].

2. Upravlenie po vzaimodejstviju s rabotodateljami. Oficial'nyj sajt JuRGPU (NPI) [Department for interaction with employers. Official website SRSPU (NPI)]. [Jelektronnyj resurs] URL: https://www.npi-tu.ru/index.php?id=111.

3. Goliusova Ju. V., Kljucharev G.A. O strategijah zanjatosti sovremennoj molodezhi [On employment strategies for modern youth]// Rossija reformirujushhajasja [Russia is being reformed]. — 2017. — №15. — Pp. 72-90.

4. Postanovlenie Pravitel'stva Rostovskoj oblasti ot 15 fevralja 2016 g. №80 «Ob utverzhdenii Regional'nogo perechnja naibolee vostrebovan- nyh na rynke truda, novyh i perspektivnyh professij i special'nostej, trebujushhih srednego professional'nogo obrazovanija» [Decree of the government of the Rostov region of February 15, 2016 №80 «On approval of the Regional list of the most popular in the labor market, new and promising professions and specialties requiring secondary vocational education»].

5. Rubinskaja Je. D., Savchenkova I.N. Rynok truda Rostovskoj oblasti i inostrannye studenty: novye podhody $\mathrm{k}$ resheniju problem deficita rabochej sily [The labor Market of the Rostov region and foreign students: new approaches to solving the problems of labor shortage] // Vestnik Rostovskogo gosudarstvennogo jekonomicheskogo universiteta (RINH) [Bulletin of the Rostov state University of Economics (RSUE)]. — 2017. №1 (57). - Pp. 47-55.

6. Nurtdinova A.F., Chikanova L.A. Differenciacija regulirovanija trudovyh otnoshenij kak zakonomernost' razvitija trudovogo prava [Differentiation of regulation of labor relations as a pattern of development of labor law] // Zhurnal rossijskogo prava [Journal of Russian law]. 2015. — №6 (222). - Pp. 68-82.

7. Saksel'ceva L. Ja., Tarskij Ju. I. Problemy zanjatosti i trudoustrojstva molodezhi $v$ fokuse sociologii [Problems of employment and youth employment in the focus of sociology] // Vestnik PAGS [PAGS Bulletin]. - 2016. - №4(55). - Pp. 85-91.

8. Rynok truda i zanjatost' naselenija. Federal'naja sluzhba gosudarstvennoj statistiki [Labor Market and employment. Federal state statistics service] [Jelektronnyj resurs] - URL: https://rostov.gks.ru/folder/29049.

9. Kapeljuk Z.A., Kapeljuk S.D. Issledovanie roli jekonomicheskih faktorov $v$ differenciacii zanjatosti naselenija [Investigation of the role of economic factors in the differentiation of employment] // Obshhestvo: politika, jekonomika, pravo [Society: politics, Economics, law]. - 2019. - №2 (67). — Pp. 25-29.

10. Omarova K.A., Kucenko D.S., Nurmagomedova R.K. Rynok truda Severo-Kavkazskogo federal'nogo okruga: analiz situacii i sodejstvie regional'noj zanjatosti [Labor Market of the North-Caucasian Federal district: analysis of the situation and to promote regional employment] // RPPJe. — 2018. — №12 (98). — Pp. 260-267. 


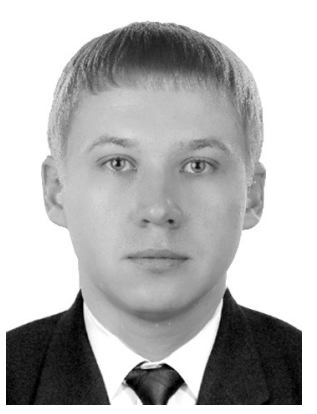

Косач Геннадий Евгеньевич - аспирант Южно-Российского государственного политехнического университета (НПИ) имени М.И. Платова. Сфера научных интересов - социология молодежи, социология занятости, математическое моделирование социологических процессов.

Kosach Gennady Eygenievich — Postgraduate Student, Platov South Russian State Polytechnic University (NPI). Research interests: youth sociology, employment sociology, mathematical modeling of sociological processes.

346428 , г. Новочеркасск, ул. Просвещения, 132

132 Prosveshcheniya st., 346428, Novocherkassk, Russia

E-mail: ccar@mail.ru 